\title{
Prediction of fatigue life of reinforced concrete bridges using Fracture Mechanics
}

\author{
M. Rocha \& E. Brühwiler \\ École Polytechnique Fédérale de Lausanne (EPFL), Switzerland
}

\begin{abstract}
With the occurrence of higher and more frequent axle loads, bridges are more solicited by fatigue loading. Bridge elements like deck slabs are subjected to a high number of stress cycles at relatively small stress magnitudes. The application of Fracture Mechanics as a useful tool for the analysis of fatigue crack growth in steel elements was demonstrated by Paris et al. in the early 1960s. With respect to reinforced concrete, the fatigue strength of the steel reinforcement is determinant. The fatigue behaviour of the steel reinforcement is similar to that of structural steel. The fatigue relevant parameters are the stress ranges, the number of fatigue cycles and stress concentrations. This paper presents a study to predict the fatigue life of steel reinforcement based on the Paris law. The method will be validated by a case study.
\end{abstract}

\section{INTRODUCTION}

During the whole life of a bridge, road and rail traffic loading produce large numbers of repetitive loading cycles in bridge elements which can thus become susceptible to fatigue damage. A reinforced concrete bridge deck may experience up to $7 \cdot 10^{8}$ stress cycles during the course of its 120 year lifespan, thus it is important to be able to assess the fatigue performance of such structures.

In reinforced concrete structures, the fatigue strength of the steel reinforcement (rebar) is determinant since the fatigue failure of concrete is unlikely to occur if the concrete is in good condition, i.e. concrete is not suffering from any deterioration mechanism (cracking) due to bar corrosion, frost or alkali-aggregate reaction (Plos et al. 2007).

Fatigue safety of reinforced concrete bridge decks includes a fatigue safety check of the rebars, and existing knowledge in fatigue behaviour of steel structures can be adopted. Fatigue failure of the steel is described in the crack initiation period, which includes crack nucleation and micro crack growth, followed by a stable crack growth period and the final failure phase. As the rebars are ribbed, the presence of stress concentrations at the root of those ribs may initiate crack growth.

When the rebar is solicited by fatigue and the fracture surface is macroscopically examined, it is often possible to identify a fairly smooth surface where the dominant fatigue crack has formed and a rougher surface (Fig. 1) which corresponds to the fi-

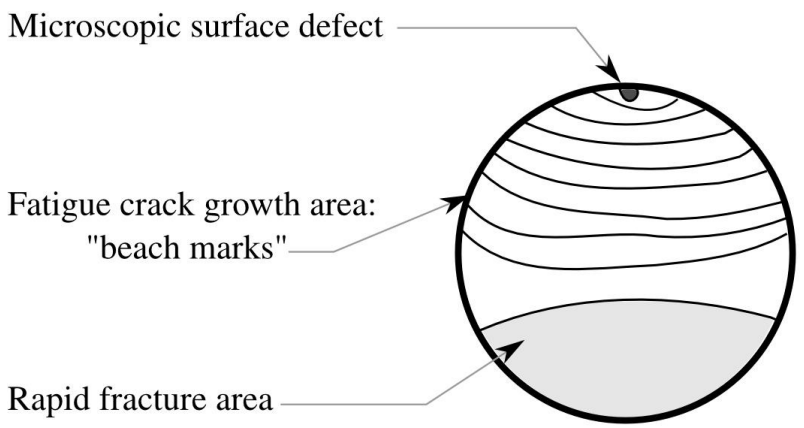

Figure 1. Cross section of the rebar surface with fatigue crack evolution.

The fracture surface also can reveal the point of crack initiation since the "beach marks" in the fatigue crack growth area point back towards the fracture origin (ASM Handbook, 1996).

\section{FRACTURE MECHANICS APPROACH}

The fatigue life of the rebars can be predicted by the Fracture Mechanics based on the principle that the stress state near to the crack tip is uniquely described by a single parameter, the stress intensity factor $K$, or under cyclic loading conditions, the 
stress intensity factor range, $\Delta K$, as shown by the equation:

$$
\Delta K=\Delta \sigma \sqrt{\pi a} Y
$$

where $\Delta \sigma$ is the applied cyclic stress range, $a$ is the crack size and $Y$ is a shape factor which depends on the element and crack geometry.

The cyclic stress intensity factor $\Delta K$ associated to the Paris law provides the number of fatigue cycles to propagate a crack under an applied stress range. The Paris law equation (Paris et al. 1961) is valid only for stable crack propagation and described by the following expression:

$$
\frac{d a}{d N}=C \Delta K^{m}
$$

where $d a / d N$ is the crack growth rate, $C$ and $m$ are material (fatigue detail) constants experimentally obtained. In order to study the fatigue crack propagation of the rebars using the Fracture Mechanics approach, the presence of an initial flaw, $a_{0}$ on a cylindrical steel bar in form of a semi-circular crack at the surface and perpendicular to the steel bar axis is assumed (Fig. 2).

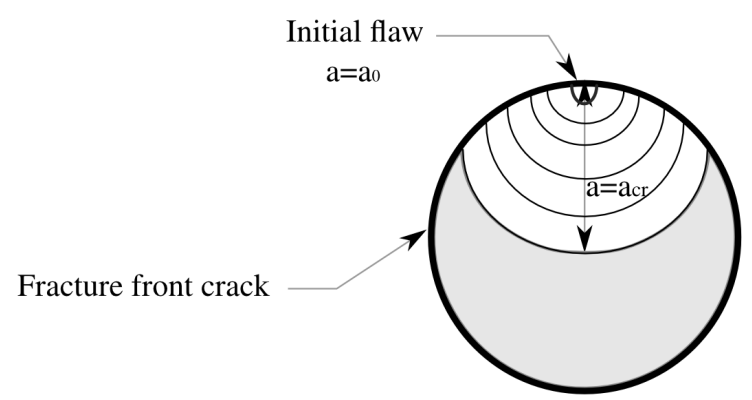

Figure 2. Rebar cross section with initial flaw and crack at fracture.

Stable crack growth is assumed from the initial flaw and the Paris law is applied for the crack growth calculations. Fracture of the rebar is estimated when the crack reaches the critical crack depth, $a=a_{c r}$ as determined considering the fracture toughness of the steel.

\subsection{Critical crack depth}

Rebar fracture occurs when the crack depth reaches $a=a_{c r}$ where the applied stress $\sigma$ is equal to the strength of the remaining cross section. Assuming a fatigue test where the stress range is constant, that stress corresponds to the superior stress level, thus $\sigma=\sigma_{\text {sup }}$.

Critical crack depth $a_{c r}$ for a brittle fracture of the rebars is given by the equation: $a_{c r}=\frac{1}{\pi}\left(\frac{K_{I c}}{Y_{c r} \sigma_{\text {sup }}}\right)^{2}$

where $Y_{c r}$ is the shape is factor for $a_{c r}$ and $K_{I c}$ is the fracture toughness of the steel. This equation is deduced from the equation 1 putting $Y=Y_{c r}$ and $K=K_{I c}$.

The fracture toughness or the critical value for the stress intensity factor $K_{I c}$ is a material constant determined experimentally on pre-cracked specimens. There is also an empirical relation between the impact strength of the Charpy test and the $K_{I c}$ value. The influence of variations of this value is very small on the fatigue life (Herwig, 2008) and a round value $K_{I c}=3000 \mathrm{Nmm}^{-3 / 2}$ may be taken.

The shape factor $Y$ for a semi-circular crack in round bars (Fig. 2), under pure membrane stress conditions and given by the expression (BS 7910, 1999):

$Y=\frac{\frac{1.84}{\pi}\left\{\tan \left(\frac{\pi a}{4 r}\right) /\left(\frac{\pi a}{4 r}\right)\right\}^{0.5}}{\cos \left(\frac{\pi a}{4 r}\right)}$.

$\left[0.752+2.02\left(\frac{a}{2 r}\right)+0.37\left\{1-\sin \left(\frac{\pi a}{4 r}\right)\right\}^{3}\right]$

where $a$ is the crack depth and $r$ is the radius of the bar. This equation is only valid for a crack depth lower than 0.6 times the bar diameter, which covers the domain of rebar crack growth calculations.

\subsection{Plastic zone size}

When a crack grows under cyclic loading, local plasticity at the crack tip controls both fracture and crack growth and the plastic zone size can be calculated as a function of $K$. LEFM can be applied to analyse the crack propagation if the plastic zone at the crack tip is small compared to the surrounding $K$ field.

A plane strain condition characterizes the local deformation behaviour in the $K$ field when the following equation is satisfied:

$$
a, B \geq 2.5\left(\frac{K}{f_{y}}\right)^{2}
$$

where $B$ is the specimen thickness, $a$ the crack depth and $f_{y}$ is the yield strength of the material. If this criterion is not satisfied, plane stress behaviour is present at the crack tip.

The plastic zone size estimated for fatigue cracks is based on calculations for monotonic loading. The 
monotonic plastic zone size $2 r_{p}$ is obtained by the equation:

$2 r_{p}=\frac{1}{\pi}\left(\frac{K}{f_{y}}\right)^{2}$

Considering the plane stress condition for the rebars, the cyclic plastic zone size $2 r_{p}^{\prime}$ for $R \geq 0$ corresponds to $1 / 4$ of the monotonic plastic zone and is given by the following equation:

$2 r_{p}=\frac{1}{4 \pi}\left(\frac{\Delta K}{f_{y}}\right)^{2}$

LEFM application is valid for $r_{p} \leq a / 8$ and $r_{p} \leq \beta / 8$ which shows that the plastic zone at the crack tip must be small compared to both the crack length and the geometrical dimensions of the specimen. Moreover, the nominal stress in the crack plane should often be less than $80 \%$ of the yield strength since a plasticity correction of approximately $20 \%$ is required for $K$ (Stephens et al. 2001).

The stress intensity factor $K$ controls the crack growth and the crack tip plastic zone size. If the plastic zone size or applied stress is a large fraction of the crack size or the yield strength, respectively, the assumptions of the LEFM can be violated due to the excessive plasticity at the crack tip. However, as the cyclic plastic zone size is usually much smaller than the monotonic plastic zone size, the LEFM is often valid and applied to study the fatigue crack growth).

\subsection{Crack growth regime}

The fatigue life of the rebars until failure has been divided in three regions according to the figure 3 :

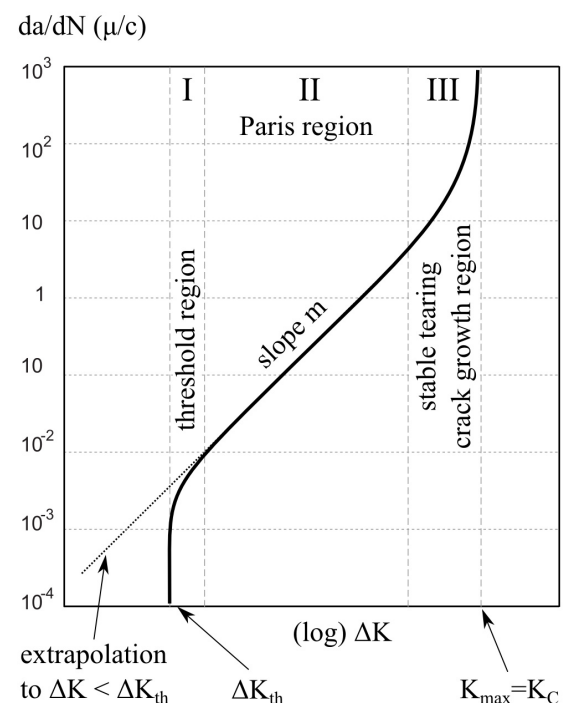

Figure 3. Stages of crack propagation (after Schijve, 2001).
The three regions in the $d a / d N-\Delta K$ graph are defined as (I) the $\Delta K$ threshold region, (II) the Paris $\Delta K$ region or stable crack propagation region and (III) unstable crack propagation region.

The vertical asymptotes at the lower $\Delta K$ boundary of the region $\mathrm{I}$, where $\Delta K=\Delta K_{t h}$, indicates that for $\Delta K$ values below this $\Delta K_{t h}$ the crack does not grow or the crack growth rate is low. The asymptote at the upper $\Delta K$ boundary of the region III occurs for a $\Delta K$ cycle with $K_{\max }=K_{c}$, i.e., $K_{\max }$ reaches the critical value which leads to complete failure of the specimen.

\subsection{Threshold Stress Intensity Factor $\Delta K_{\text {th }}$}

Values of $\Delta K_{\text {th }}$ are usually less than $10 M P a \sqrt{m}$ for steels (Stephens et al. 2001). Work undertaken by Barsom and Rolfe (Dowling, 1993) provides a lower bound stress intensity factor threshold for various steels. The $\Delta K_{t h}$ values are given by the following equations:

$$
\Delta K_{t h}=191 \mathrm{Nmm}^{-3 / 2}, R \leq 0.17
$$

$\Delta K_{t h}=222.4(1-0.85 R) \mathrm{Nmm}^{-3 / 2}, R \geq 0.17$

where the stress ratio is $R=\sigma_{\min } / \sigma_{\max }$. According to these equations, $\Delta K_{\text {th }}$ tends to decrease as $R$ increases.

\subsection{Estimation of the minimum crack length for the LEFM application}

Crack growth rate near threshold is generally underestimated using LEFM when the criterion for a large crack is not assumed. El Haddad et al. 1979 (by Ritchie \& Murakami 2003) estimated the transition from short to large crack length $a_{0}$, where the LEFM is valid, shown in the equation:

$$
a_{0}=\frac{1}{\pi}\left(\frac{\Delta K_{t h}}{\beta \Delta \sigma_{\mathrm{lim}}}\right)^{2}
$$

where $\Delta \sigma_{\text {lim }}$ corresponds to the fatigue limit and the $\beta$ value is the one corresponding to the crack depth where $\Delta K=\Delta K_{t h}$.

Fatigue limit, also called endurance limit, is the minimum stress amplitude that can nucleate a crack that grows until failure. A micro crack can be initiated below the fatigue limit but it does not grow into macro cracks due to microstructural barrier (Schijve, 2003). The fatigue limit for rebar can be obtained 
from the $S-N$ curves which provide the fatigue strength in relation to the number of cycles.

\subsection{Crack growth calculation based on Paris law}

According to this approach, the number of cycles to propagate a crack from the depth $a=a_{i}$ to $a_{j}$ is analytically calculated by crack increments through the integration of the Paris law equation which leads to the following equation:

$N_{i j}=\frac{1}{D \alpha \pi^{m / 2} \beta^{m} \Delta \sigma^{m} a_{i}^{\alpha}}\left[1-\left(\frac{a_{i}}{a_{j}}\right)^{\alpha}\right]$

where $N_{i j}$ is the number of cycles which increase the crack depth from $a=a_{i}$ to $a_{j}, \alpha=m / 2-1, \beta$ is the average value between $a_{i}$ and $a_{j}$. The constant values are $m=3$ and $D=2 \cdot 10^{-13}$ for the steel (Hirt et al. 2006).

The number of cycles to propagate the crack $N_{\text {prop }}$ is counted for each $\Delta a$ increment and the fracture cycle number corresponds to the sum of all increment until fracture. The fatigue crack propagates only if $\Delta K>\Delta K_{t h}$.

\section{CASE STUDY}

This report investigated the fatigue life of the rebars of one standard bridge type, i.e. single span girder with two webs that was used to build bridges of multiple spans in Brazil (Fig. 4). These bridges carry a single railway track which is trafficked by mineral ore trains.

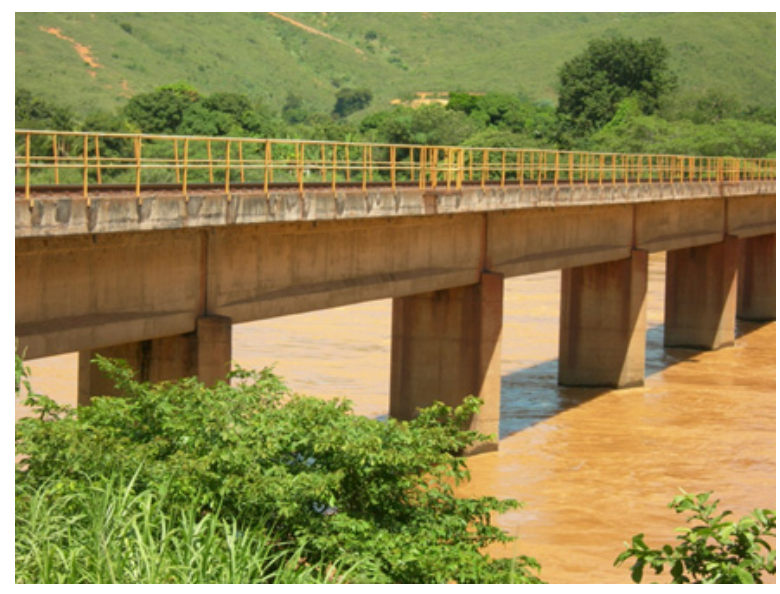

Figure 4. Reinforced concrete railway bridge in Brazil.

The reinforced concrete bridge under investigation was built in 1970 and is composed of three spans of $18.7 \mathrm{~m}$ each (Fig. 5). The concrete has a compressive strength of $f_{c k}=31.2 \mathrm{MPa}$ and rebar yield strength of $f_{y}=500 M P a$. The single span beams show flexural cracks in the tension zone. The reinforced concrete bridge does not show any significant deterioration that would impair the structural resistance.
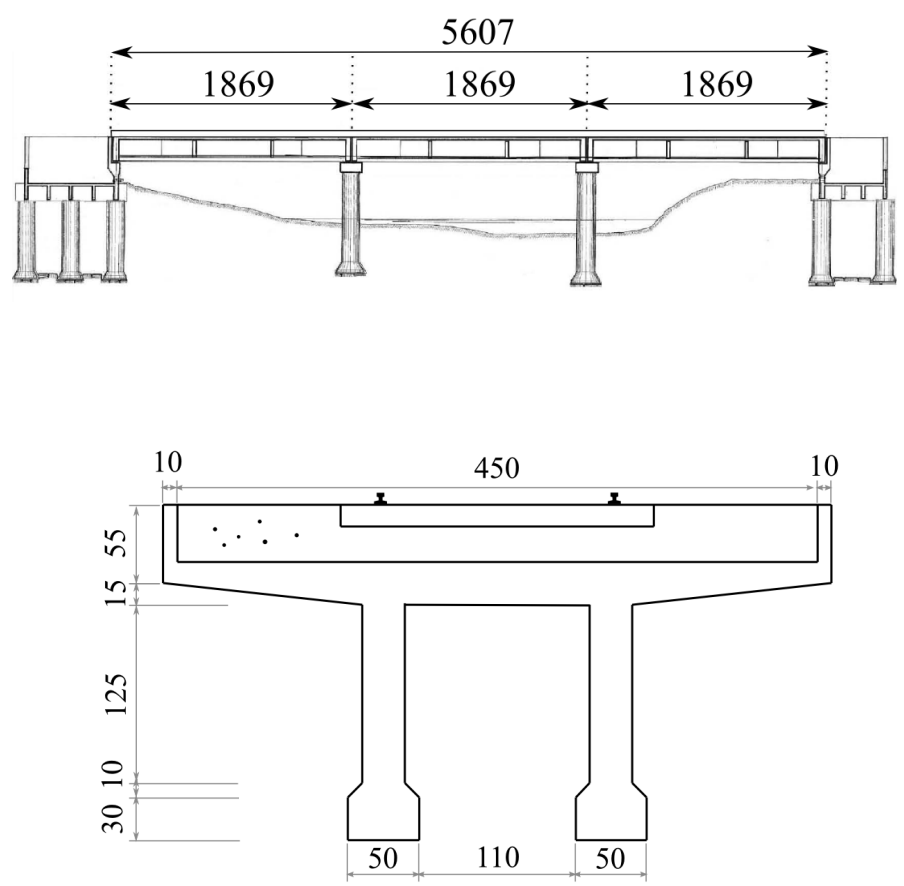

Figure5. Geometry of the bridge (cm): (a) Elevation (b) Cross section.

Freight trains with different wagon types cross the bridge. Full ore wagons represent the worst case load effect and show an axle load of $247 \mathrm{KN}$. In the future, the maximum axle load will increase to $325 \mathrm{KN}$. Approximately 8740 trains cross the bridge per year (24 trains per day, 7 operating days per week and 52 weeks per year).

Due to the planned increase in traffic volume and axle loads, the fatigue life of the most solicited rebars, which show a diameter of $25.4 \mathrm{~mm}$, was analysed using the Fracture Mechanics approach. The crack growth calculations were performed assuming the number of cycles $N \leq 10^{8}$ for current traffic loads and increased traffic loading.

Stress range calculated in the rebars in the bottom part of the two main girders due to the current maximum railway loading and increased by a dynamic factor $\varphi=1.04$ (EN 1991-2, 2003) was $\Delta \sigma=79.8 M P a$. The stress ratio in the rebars was $R=0.48$ since the action effect due to dead load is about the same as the one due to traffic loading.

The characteristic fatigue strength of straight and bent rebars is $\Delta \sigma_{R S k}=162.5 \mathrm{MPa}$ at a number of cycles $N^{*}=10^{6}$ (Fig. 6). 


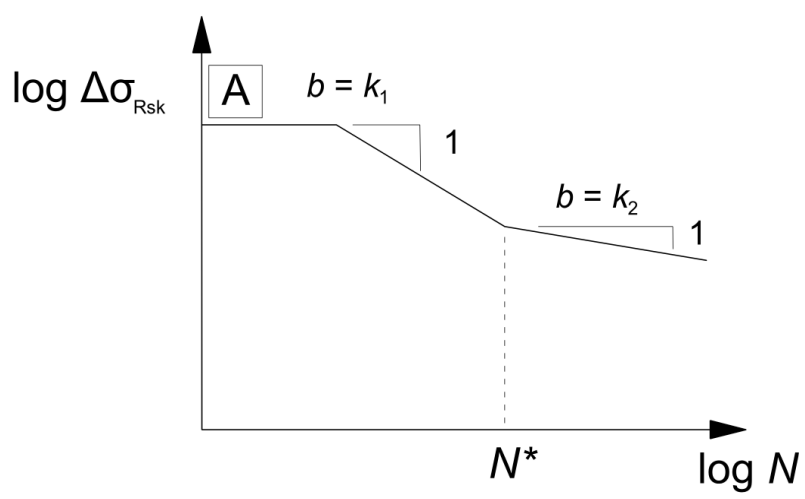

Figure 6. S-N curve for reinforcing and prestressing steel taken from EN 1992-1-1:2004.

The slopes of the S-N curve are $k_{1}=5, k_{2}=9$ and $A$ correspond to the reinforcement at yield. The fatigue strength $\Delta \sigma_{R s d}$ at $\mathrm{N}$ cycles is $\Delta \sigma_{R S k} / \gamma_{S, f a t}$, where $\gamma_{S, \text { fat }}$ is a partial safety factor for fatigue resistance equal to 1.15 (EN 1992-1, 2004).

Considering the stress level $\Delta \sigma=79.8 \mathrm{MPa}$ due to the current loads, the number of cycles to fracture the rebar is given in the Figure 7. The crack grows from an initial depth $a_{0}$ until a predefined depth $a_{f r}=15 \mathrm{~mm}$ where the crack is assumed.

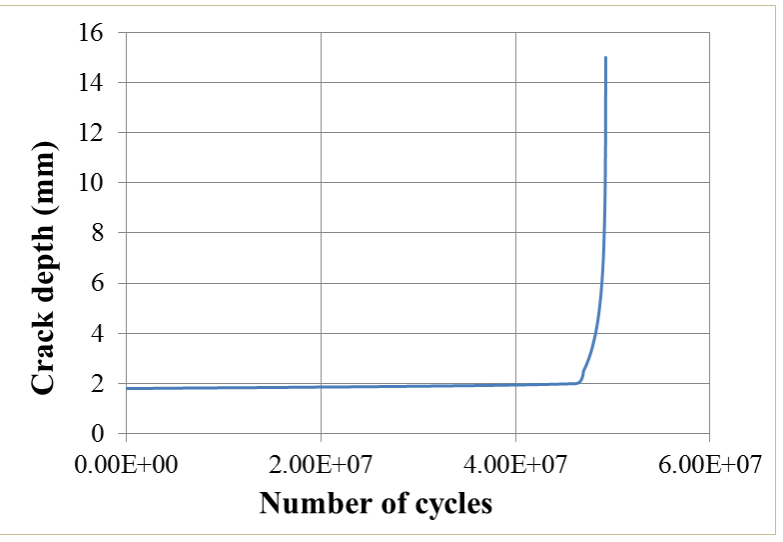

Figure 7. Calculated crack growth curve for current axle loads of $247 \mathrm{KN}$.

The minimum crack length where the LEFM is valid was obtained for $a_{0}=1.8 \mathrm{~mm}$ since the crack propagates when $\Delta K>\Delta K_{t h}$. As it is very unlikely that the rebars show any flaw with this size, it may be stated that, based on the LEFM, crack growth is not likely to occur for $\Delta \sigma=79.8 \mathrm{MPa}$. The cyclic plastic zone size at the crack tip, calculated from the equation 7 , was very small compared to the crack length $a_{0}$.

Considering the increased future rail traffic with maximum axle loads of $325 \mathrm{KN}$, the stress range generated in the rebars and increased by the dynamic factor $\varphi=1.04$ was $\Delta \sigma=104.7 \mathrm{MPa}$. The stress ra- tio is $R=0.44$ since the stress due to the dead load was obtained $\sigma=82.3 \mathrm{MPa}$. The number of cycles until fracture in relation to the crack depth from $a_{0}$ to $a_{f r}=15 \mathrm{~mm}$ is given in the Figure 8 .

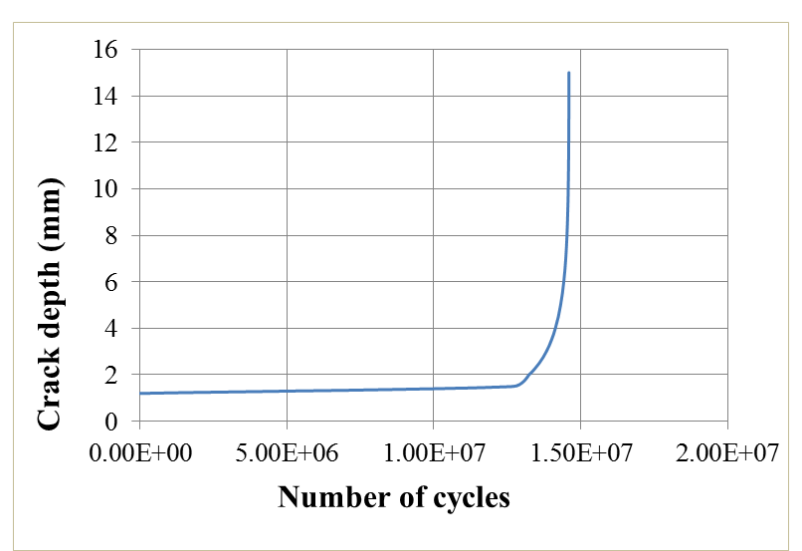

Figure 8. Calculated crack growth curve for increased axle loads of $325 \mathrm{KN}$.

LEFM, thus Paris law, can be applied to calculate the crack growth in the rebars due to the increased future loads since a minimum crack length $a_{0}=1.2 \mathrm{~mm}$ is assumed. However, for $a_{0}<1.2 \mathrm{~mm}$, cracks can propagate at a $\Delta K$ value below the threshold for large cracks. Sometimes these cracks grow faster than cracks at the same nominal $\Delta K_{\text {th }}$ value (Ritchie \& Murakami, 2003). Consequently, the crack growth calculations when $\Delta K<\Delta K_{\text {th }}$ can be underestimated by the LEFM approach.

According to the LEFM, an increase of $25 \%$ in the axle load can reduce by $70 \%$ the fatigue life of the rebar as demonstrated in Figures 7 and 8. Considering 8740 trains passing on the bridge per year and the stress range generated due to the future axle loads, the bridge exhibits a very large remaining fatigue life of the bridge since approximately 15 millions cycles are theoretically required to fracture the rebar.

Moreover, the crack growth calculations shown in Figures 7 and 8 correspond to the fracture of the first rebar of the lowest layer and additional fatigue life can be provided by the remaining rebars (Herwig, 2008).

The reduction in fatigue life can also be estimated for an increased number of trains calculated through the equation:

$N_{\text {tot }}=(1+\alpha) N_{\text {tot, } r e f}$

where $\alpha$ is the traffic increase in percentage assuming that only the number of trains is changed and $N_{\text {tot, ref }}=8740$ which corresponds to the total number of trains passing on the bridge per year. 


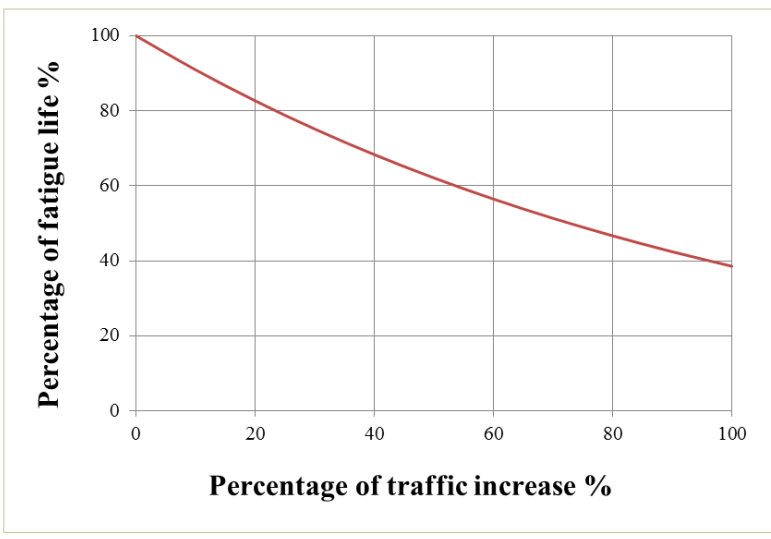

Figure 9. Fatigue life variation as a function of the increase in the number of trains.

According to Figure 9, an increase of $20 \%$ in the number of trains reduces the fatigue life of the bridge by approximately $20 \%$. Therefore, the effect of the increased traffic volume is not as noticeable as the effect of higher axle loads.

\section{CONCLUSIONS}

Fatigue life of the rebar can be predicted using Linear Elastic Fracture Mechanics since the cyclic plastic zone is very small at the crack tip and it is assumed the crack growth only if $\Delta K>\Delta K_{t h}$. The reinforced concrete bridge presented in this study is safe with respect to fatigue for the current and increased loads of the future. The rebars in the tensile zone of the bridge girder are solicited by a rather low fatigue stress range which shows that the bridge has large reserves in relation to fatigue based on the LEFM approach.

\section{REFERENCES}

ASM Handbook 1996. Fatigue and Fracture. Ohio: ASM International.

BS 7910 1999. Guide on methods for assessing the acceptability of flaws in metallic structures. London: British Standards Institution.

Dowling, N.E. 1993. Mechanical Behavior of Materials. New Jersey: Prentice Hall.

EN 1991-2 2003. Eurocode 1: Actions on structures - part 2: Traffic loads on bridges. Brussels: CEN.

EN 1992-1-1 2004. Eurocode 2: Design of concrete structures - Part 1-1: General rules and rules for buildings. Brussels: CEN.

Herwig, A. 2008. Reinforced concrete bridges under increased railway loads - fatigue behavior and safety measures. $P h D$ Thesis no. 1040. ENAC-MCS. École Polytechnique Fédérale de Lausanne. Lausanne, Switzerland.

Hirt, M.A., Bez, R. \& Nussbaumer, A. 2006. Construction métallique: notions fondamentales et méthodes de dimensionnement, nouvelle édition revue et adaptée aux nouvelles normes de structures. Traité de Génie Civil de l'Ecole Po- lytechnique Fédérale de Lausanne, vol. 10. Lausanne, Switzerland.

Paris, P.C., Gomez, M.P. \& Anderson, W.E. 1961. A rational analytic theory of fatigue. The Trend in Engineering, 13, 9-14.

Plos, M., Gylltoft, K., Lundgren, K., Elfgren, L., Cervenka, J., Brühwiler, E., Thelandersson, S. \& Rosell, E. 2006. Structural assessment of concrete railway bridges: non-linear analysis and remaining fatigue life. IABMAS'06: $3 \mathrm{rd} \mathrm{In-}$ ternational Conference on Bridge Maintenance, Safety and Management, Porto, Portugal, July 16-19.

Ritchie, R.O. \& Murakami, Y. 2003. Comprehensive Structural Integrity: Fracture of materials from nano to macro: cyclic loading and fatigue. Oxford: Elsevier.

Schijve, J. 2001. Fatigue of Structures and Materials. Dordrecht: Kluwer.

Schijve, J. 2003. Fatigue of Structures and Materials in the 20th Century and the State of the Art. International Journal of Fatigue, 25, 679-702.

Stephens, R.I., Fatemi, A., Stephens, R.R. and Fuchs, H.O. 2001. Metal Fatigue in engineering. New York: Wiley Interscience. 